\title{
Article \\ Numerical Simulation Model for Evaluating Protection Measures of Blast Furnace Hearth
}

\author{
Lei Wang ${ }^{1}\left(\mathbb{D}\right.$, Liangyu Chen $^{1, *}$, Yang Li $^{2}{ }^{(D)}$ and Jiaocheng Ma ${ }^{1}$ \\ 1 School of Mechanical Engineering and Automation, Northeastern University, NO. 3-11 Wenhua Road, \\ Shenyang 110819, China; 1910079@stu.neu.edu.cn (L.W.); majiaocheng@163.com (J.M.) \\ 2 Jiangsu Xugong Construction Machinery Research Institute Co., Ltd., 26 Tuolanshan Road, \\ Xuzhou 221004, China; yang.li.neu@gmail.com \\ * Correspondence: lychen@mail.neu.edu.cn
}

Citation: Wang, L.; Chen, L.; Li, Y.; Ma, J. Numerical Simulation Model for Evaluating Protection Measures of Blast Furnace Hearth. Processes 2022, 10, 481. https://doi.org/ $10.3390 /$ pr10030481

Academic Editor: Evangelos Tsotsas

Received: 22 December 2021

Accepted: 24 February 2022

Published: 27 February 2022

Publisher's Note: MDPI stays neutral with regard to jurisdictional claims in published maps and institutional affiliations.

Copyright: (C) 2022 by the authors. Licensee MDPI, Basel, Switzerland. This article is an open access article distributed under the terms and conditions of the Creative Commons Attribution (CC BY) license (https:// creativecommons.org/licenses/by/ $4.0 /)$.

\begin{abstract}
The blast furnace (BF) hearth is critical for determining the life of a BF. Irreversibly eroded hearths can be caused by high-temperature molten iron erosion, alkali metal corrosion, and thermal stress. When serious depression erosion occurs in the hearth, furnace protection measures can prevent the erosion from expanding and ensure the safe operation of the BF. At present, furnace protection measures and furnace protection strength are mostly selected based on engineering experience. In this paper, a three-dimensional (3D) computational fluid dynamics (CFD) numerical model of BF hearth with elephant-type depression erosion was established to predict and evaluate the effect of furnace protection measures. At the same time, the phase change behavior of hot iron solidification was also considered. A numerical model was used to analyze common furnace protection measures such as increasing furnace hearth cooling, closing the tuyere, reducing the tapping productivity, and reducing the tapping temperature. The calculation results are consistent with actual furnace protection experience.
\end{abstract}

Keywords: blast furnace hearth; furnace protection measures; numerical simulation; solidification and melting; porous medium

\section{Introduction}

The $\mathrm{BF}$ is a type of large ironmaking equipment. The hearth located in the lower part of the BF is a frequent site of safety accidents [1-4]. During the BF production process, the refractory lining of the hearth comes into direct contact with high-temperature molten iron. As a result of molten iron erosion, alkali metal corrosion, and thermal stress, irreversible local depression erosion occurs in the hearth. If the erosion continues to develop, burn through accidents will occur, resulting in severe casualties and causing extensive property loss for the business. To ensure the safety of the hearth, some furnace protection measures are adopted to slow down or prevent the expansion of local depression erosion [5-8]. The general measures for furnace protection are closing tuyere, reducing smelting intensity, improving cooling intensity, etc. The practice has proved that these measures for furnace protection are feasible.

Improving the cooling intensity of the furnace hearth can reduce the temperature of its hot surface $[9,10]$. The accumulation of heat in the hearth is avoided in this way. It promotes the formation and adhesion of the solidified iron layer. If there is a scale or air gap in the hearth, it has a great impact on the heat transfer system [11-13]. The heat cannot be transferred in time. The temperature of the hearth rises locally. Adjusting the blast regime can reduce the oxygen supply in the erosion area. The chemical reaction rate above the erosion area is reduced. And the hot iron generation at the corresponding location is reduced. After reducing the productivity of tapping [14], the flow rate of hot iron will decrease. The circulation of hot iron will be alleviated, and the erosion of hot iron to the furnace lining is slowed down. 
Under the forced cooling of the external cooling system, the temperature of the hot iron near the hearth lining decreases. When the temperature is lower than the freezing temperature $\left(1150{ }^{\circ} \mathrm{C}\right)$, the hot iron will solidify. And it adheres to the hot surface of the furnace lining. A protective layer of solidified iron is formed on the surface of the furnace lining $[15,16]$. The protective layer can isolate hot iron from the lining wall, effectively reduce the erosion of hot iron to the hearth lining, and simultaneously reduce the chemical erosion of harmful chemical substances in the hot iron to the hearth lining. The main purpose of $\mathrm{BF}$ protection is to push the $1150{ }^{\circ} \mathrm{C}$ isothermal surface into the hearth and promote the formation of a stable iron layer on the hot surface of the hearth lining.

In the previous research, the CFD model of the BF hearth concerning the existence of a solidified iron layer was established. Zhao et al. [17] used the solidification and melting model to establish a two-dimensional model. The encrustation phenomenon in the hearth was studied using the model. Besides, the influence of parameters on the formation of the solidified iron layer was discussed, including lining performance and structure, cooling water temperature, flow rate, and hot iron production rate. Dong et al. [12] established a transient numerical calculation model considering the solidification phase transition of hot iron. The actual measured value of the refractory material was compared and verified with the calculated value. Based on that, the state of the hearth was estimated during the long shutdown period.

At present, most of the furnace protection measures are selected based on engineering experience. There is a lack of feasible methods to evaluate and predict the furnace protection effect. This may cause an improper selection of furnace protection measures and affect the smooth flow of BF smelting production. In this study, a 3D numerical model of BF hearth with elephant-type depression erosion was established. The model combined heat transfer and computational fluid dynamics theories. The hot iron flow and solidification phase transition were also considered in the model. The calculation model was applied to evaluate the effectiveness of common furnace protection measures, such as reducing the smelting strength, increasing the cooling strength, and closing the tuyere. The thickness of the solidified iron layer was used as the evaluation index.

\section{Models and Methods}

In this study, a No. 5 BF was used as the object of study. SolidWorks was used to create the model of a BF hearth with elephant-type erosion. A mathematical model combining heat transfer, fluid dynamics, and numerical simulation of solidification and melting was developed based on the Ansys Fluent software package. The numerical model was used to simulate the flow of hot iron and the formation of a protective layer of solidified iron in the hearth. The calculation process of the solidified iron layer is shown in Figure 1.

\subsection{Physical Models}

The effective volume of the No.5 BF was $1580 \mathrm{~m}^{3}$. The hearth was made of carbon composite bricks, microporous carbon bricks, and graphite bricks, as shown in Figure 2a. The inner diameter of the taphole was $60 \mathrm{~mm}$. The angle between the taphole and the horizontal direction was $12^{\circ}$. During BF production, a certain amount of stemming was injected into the hearth through the taphole after each tapping. The stemming formed a convex mud bag attached to the inner side of the hearth near the taphole to protect the furnace wall. In this paper, stemming was simplified by using a circular platform with a height of $1000 \mathrm{~mm}$.

In the process of BF production, a large number of coke particles gather in the center of the hearth to form a deadman $[18,19]$. The consumption of the deadman and its update speed is very slow, and its shape and position are relatively stable. In the calculation model, a round, table-shaped deadman was assumed to be in the center of the hearth, as shown in Figure $2 \mathrm{~b}$. It was set as a porous medium with a porosity of 0.3 [20-23]. The porous medium model was used to reflect the effect of the deadman on the flow of the molten iron. 
The physical properties of the hot iron and solid materials are listed in Tables 1 and 2, where $T$ is the temperature, indicating that the property value changes with the temperature.

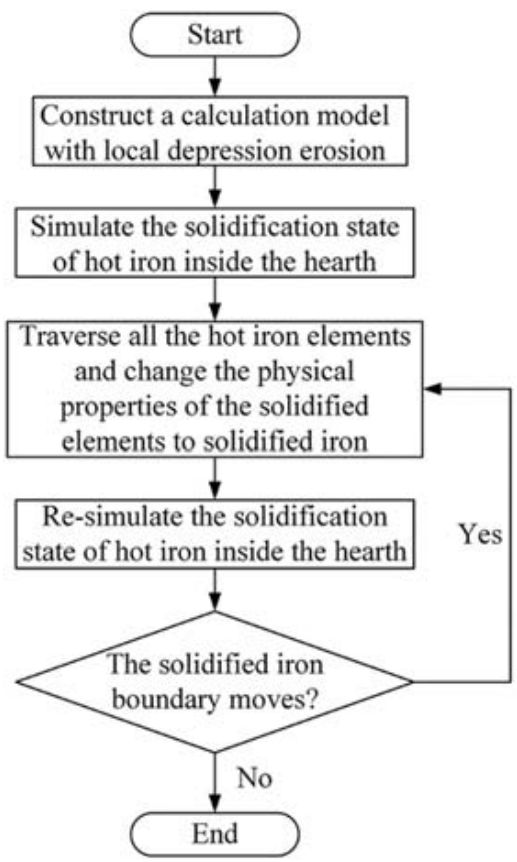

Figure 1. The calculation process of the solidified iron layer.
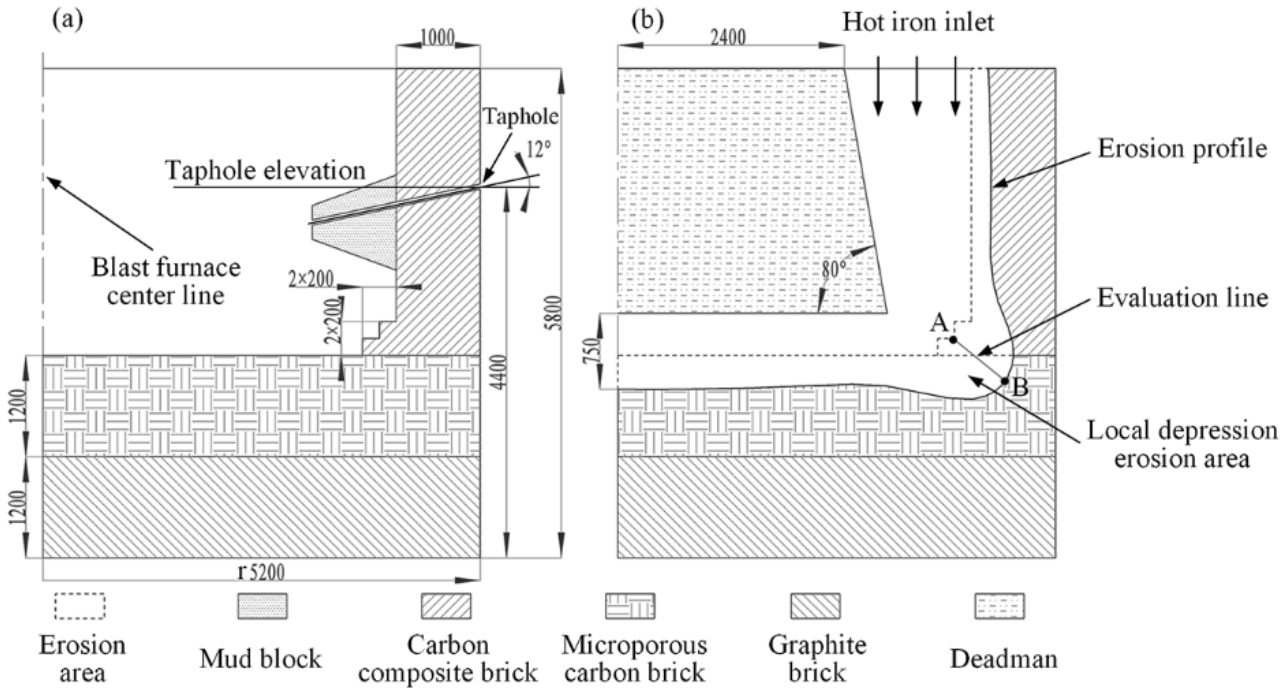

Figure 2. The hearth structure of the BF. (a) design structure of hearth lining. (b) hearth erosion profile.

Table 1. Physical properties of solid materials.

\begin{tabular}{cccc}
\hline Materials & Density $\left(\mathbf{k g} / \mathbf{m}^{\mathbf{3}}\right)$ & $\begin{array}{c}\text { Specific Heat } \\
\mathbf{( J / k g} \cdot \mathbf{K})\end{array}$ & $\begin{array}{c}\text { Thermal Conductivity } \\
(\mathbf{W} / \mathbf{m} \cdot \mathbf{K})\end{array}$ \\
\hline Graphite brick & 2180 & 840 & $46.61-0.01342 T$ \\
Microporous carbon brick & 1900 & 840 & $8.88+0.0044 T$ \\
Carbon composite brick & 2980 & 840 & $17.58-0.00499 T$ \\
\hline
\end{tabular}


Table 2. Physical properties of hot iron.

\begin{tabular}{cccc}
\hline Property & Value & Property & Value \\
\hline Density $\left(\mathrm{kg} / \mathrm{m}^{3}\right)$ & 6700 & Melting heat $(\mathrm{J} / \mathrm{kg})$ & 103,343 \\
Specific heat $(\mathrm{J} / \mathrm{kg} \cdot \mathrm{K})$ & 756 & Solidification & 1423 \\
Thermal conductivity $(\mathrm{W} / \mathrm{m} \cdot \mathrm{K})$ & $0.0158 T$ & Melting temperature $(\mathrm{K})$ & 1573 \\
Viscosity $(\mathrm{kg} / \mathrm{m} \cdot \mathrm{s})$ & 0.007 & - & - \\
\hline
\end{tabular}

Local depression erosion of the hearth lining often occurs in the furnace corner area, with a majority in the direction of a 30-60 angle with the taphole. In this paper, an elephant-type localized lining depression erosion was constructed in the furnace corner area, which is $45^{\circ}$ away from the taphole direction. The lining erosion profile is shown in Figure 2b, and a 3D model of the hearth is shown in Figure 3.

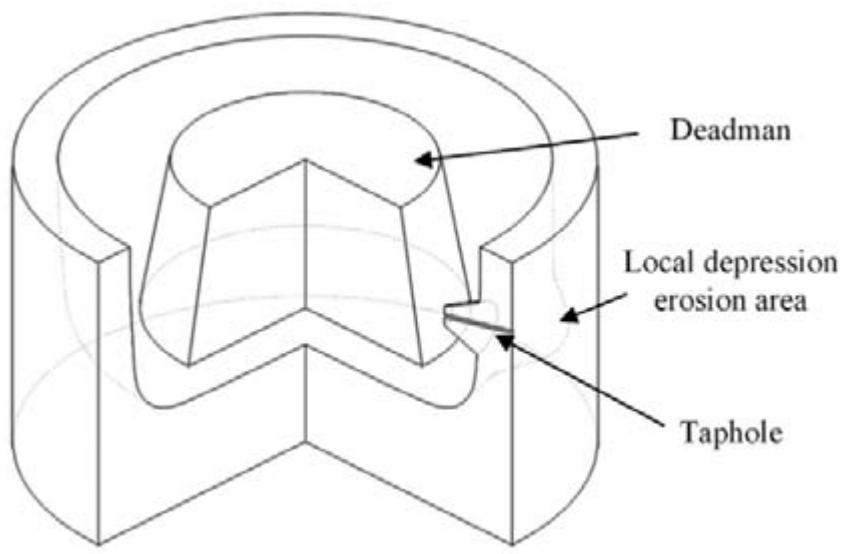

Figure 3. 3D model of the elephant-type erosion hearth.

\subsection{Methods}

The tapping of the hearth is an unsteady process. When the hearth has a long tapping time with a single taphole and a stable tapping temperature, the tapping process can be regarded as a quasi-steady-state process. The process follows the law of conservation of mass, momentum, and energy [24,25]. The k-epsilon turbulence model is used for simulation. The heat generated by the heat radiation of the furnace is relatively small. Therefore, the influence of thermal radiation is ignored in the calculation model. In actual production, the flow of molten iron inside the BF hearth is complicated. To simplify the model, the calculation model established in this paper makes the following assumptions:

(1) The hearth is under a steady tapping state.

(2) The taphole area is a coke-free area, and the molten iron inside it can flow unobstructed.

(3) The calculation model ignores the influence of the chemical reaction and heat transfer inside the hearth on the flow of molten iron.

(4) The molten iron flows into the hearth at a uniform speed.

\subsubsection{Heat Conduction Differential Equation}

This calculation model considers the working state of the hearth for continuous and stable tapping, and the fluctuation of the internal environment of the hearth is relatively small. Therefore, the heat transfer process in the hearth can be simplified to a steady-state process [26]. The coupled heat transfer process between the hot iron and the refractory 
material in the hearth can be described by the differential equation of heat conduction, as shown in Equation (1).

$$
\frac{\partial}{\partial x}\left[\lambda(T) \frac{\partial T}{\partial x}\right]+\frac{\partial}{\partial y}\left[\lambda(T) \frac{\partial T}{\partial y}\right]+\frac{\partial}{\partial z}\left[\lambda(T) \frac{\partial T}{\partial z}\right]=0
$$

where $T$ is the temperature; $\lambda(T)$ is the thermal conductivity of materials at different temperatures.

\subsubsection{Solidification and Melting Model}

Under forced cooling of the external cooling system of the hearth, the temperature of the molten iron near the lining decreases. When the molten iron temperature is lower than $1150{ }^{\circ} \mathrm{C}$, the molten iron condenses and adheres to the hot surface of the inner liner, forming a solidified iron protective layer. In this paper, the solidification and melting model was used to simulate the formation of the solidified iron layer in the hearth $[27,28]$. The enthalpy-porosity technique was used to simulate the fluid solidification and melting process. The volume fraction of the liquid at each iteration based on the enthalpy balance was calculated. The pressure drop due to the presence of solid materials was simulated by adding a source term to the momentum equation. The energy equation of the solidification and melting model is as follows:

$$
\frac{\partial(\rho H)}{\partial t}+\nabla \cdot(\rho u H)=\nabla \cdot(\lambda \nabla T)+S
$$

where $H$ is the total enthalpy of the substance $H=h+\Delta H$, which includes the sensible $(h)$ and latent $(\Delta H)$ heath enthalpies; $\rho$ is the fluid density; $u$ is the fluid velocity; and $S$ is the source term. The latent heat $(\Delta H)$ is an important parameter for determining the effect of solidification that can be described as a function of the liquid fraction.

$$
\Delta H=\omega L
$$

where $L$ is the latent heat of the material and $\omega$ is the porosity. When the liquid is completely solidified, its porosity drops to zero (the liquid volume fraction drops to zero). When the liquid is completely melted, the porosity rises to one, and the liquid flow in the corresponding area is not affected. The porosity of the liquid-solid mushy zone is between one and zero. And the size of the porosity changes with temperature. The porosity at different temperatures is:

$$
\left\{\begin{array}{ccc}
\omega=0 & \text { if } & T<T_{\text {solid }} \\
\omega=1 & \text { if } & T>T_{\text {liquid }} \\
\omega=\frac{T-T_{\text {solid }}}{T_{\text {liquid }}-T_{\text {solid }}} & \text { if } & T_{\text {solid }}<T<T T_{\text {liquid }}
\end{array}\right.
$$

where $T_{\text {solid }}$ is the solidification temperature; $T_{\text {liquid }}$ is the melting temperature.

\subsubsection{Mathematical Expression of the Deadman}

The deadman in the center of the hearth is treated as a porous medium in the calculation model [29]. The effect of porous media on the fluid was modeled by adding the momentum equation source term to the standard momentum equation, as shown in Equation (5). According to the Ergun equation and Darcy's law, the source term of the kinetic loss caused by a single and homogeneous porous medium consists of viscous loss term and inertial loss term, as shown in Equations (6)-(8).

$$
\nabla \cdot(\rho \vec{v} \vec{v})=-\nabla P+\nabla \cdot\left[\mu_{e f f}\left(\nabla \vec{v}+\nabla \vec{v}^{\mathrm{T}}\right)\right]+\rho \vec{g}+S_{i}
$$




$$
\begin{gathered}
S_{i}=-\left(\frac{\mu \vec{v}}{\alpha}+\frac{1}{2} C \rho|v| \vec{v}\right) \\
\frac{1}{\alpha}=\frac{150}{d_{c}^{2}} \frac{(1-\omega)^{2}}{\omega^{3}} \\
C=\frac{3.5}{d_{c}} \frac{(1-\omega)}{\omega^{3}}
\end{gathered}
$$

where $\rho$ is the density; $\vec{v}$ is the velocity vector; $P$ is the pressure; $\mu_{e f f}$ is the effective viscosity; $\vec{g}$ is the acceleration of gravity; $S_{i}$ is the source terms of the momentum equation; $\mu$ is the viscosity; $1 / \alpha$ is the viscous resistance coefficient; $d_{c}$ is the average diameter of the coke constituting the deadman, which is taken as $0.03 \mathrm{~m} \mathrm{[23];} C$ is the inertial resistance coefficient.

\subsubsection{Boundary Conditions}

Because of the low porosity of the deadman, hot iron flows in between the liner and the deadman. The mass flow of the hot iron in the annular area on the top surface of the model is regarded as the inlet boundary condition. The mass flow rate of the inlet can be calculated using Equation (6). The taphole is used as the outlet of the calculation model. The outlet is kept at atmospheric pressure, which equals $1.01 \times 10^{5} \mathrm{~Pa}$.

$$
m=\frac{1000\left(M_{i}+M_{s}\right)}{24 \times 60 \times 60}
$$

where $m$ is the mass flow rate; $M_{i}$ is the daily pig iron production of the BF, i.e., $M_{i}=\eta_{V} \cdot V$, $V$ and $\eta_{V}$ are the volume and volume utilization factor of the BF, respectively; and $M_{s}$ is the slag discharge, which is approximately one-third of the pig iron production.

Cooling equipment was required to protect the shaft and shell during BF production, and cooling staves made of cast iron or copper were usually arranged between the hearth and shell. In this paper, the cooling structure of the outside and bottom of the hearth were not established in the 3D structure model. In the thermofluid coupling calculation model, the convection heat transfer coefficient of the side walls of the hearth was equivalent and calculated by using the convection heat transfer boundary replacement method of the long cylinder [30]. The equivalent convection heat transfer coefficient of the side walls of the hearth $\left(h_{\mathrm{c}}\right)$ was calculated by Equations (7)-(10). The convection heat transfer coefficient of the furnace bottom was $40 \mathrm{~W} / \mathrm{m}^{2} \cdot \mathrm{K}$, and all other boundaries were adiabatic boundaries.

$$
\begin{gathered}
h_{w}=208.8+47.5 v_{w} \\
h_{1}=\gamma h_{w} \\
h_{2}=\frac{r_{1}}{r_{2}} \frac{h_{1} \lambda_{1}}{\lambda_{1}+h_{1} r_{1} \ln \left(r_{1} / r_{2}\right)} \\
h_{c}=\frac{r_{2}}{r_{3}} \frac{h_{2} \lambda_{2}}{\lambda_{2}+h_{2} r_{2} \ln \left(r_{2} / r_{3}\right)}
\end{gathered}
$$

where $h_{w}$ is the equivalent convective heat transfer coefficient on the surface of the cooling wall water pipe; $v_{w}$ is the flow rate of cooling water; $h_{1}$ is the equivalent convective heat transfer coefficient at the center surface of the cooling wall water pipe; $\gamma$ is the cooling specific surface area; $h_{2}$ and $h_{c}$ are the equivalent convective heat transfer coefficients of the cold surface of the packing layer and the cold surface of the hearth sidewall respectively; $r_{1}$ is the distance from the center of the cooling water pipe to the center of the hearth; $r_{2}$, $r_{3}$ are the radii of the outer and inner walls of the packing layer; $\lambda_{1}, \lambda_{2}$ are the thermal conductivity of the cooling wall and packing layer respectively. 


\subsubsection{Mesh Generation}

The polyhedral mesh technology is used to discretize the computational model. The polyhedral mesh can obtain higher calculation accuracy with fewer meshes. To improve the convergence of the model, a five-layer expansion layer mesh is set at the liquid-solid interface. After the mesh independence analysis, the number of divided meshes is 1,313,196. The fluid area has 736,331 meshes, and the solid area has 576,865 meshes. The final divided calculation mesh is shown in Figure 4.

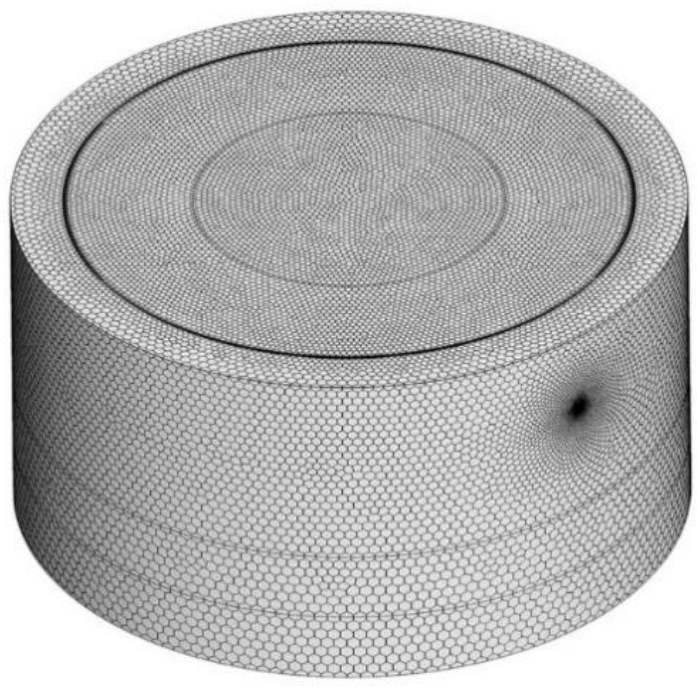

Figure 4. The mesh of the computational model.

\section{Results and Discussion}

The general furnace protection measures were compared and studied using the evaluation model, such as strengthening hearth cooling, closing tuyeres, and reducing tapping productivity. An evaluation line was set in the central area of the local depression erosion, shown in Figure 2b, and the coordinates of the two endpoints are A $(2828.4 \mathrm{~mm}, 2828.4 \mathrm{~mm}$, $2600 \mathrm{~mm})$ and $B(3177.7 \mathrm{~mm}, 3177.7 \mathrm{~mm}, 2186.8 \mathrm{~mm})$. The volume fraction of hot iron on the evaluation line was extracted to quantitatively evaluate the solidification state of the hot iron in the local depression erosion area. When the volume fraction was zero, the hot iron was completely solidified.

\subsection{Calculation of Normal Production State}

Firstly, the normal production (without any furnace protection measures) was analyzed and calculated. In this study, the specific cooling surface area of the hearth stave was 1.0. The distance from the central surface of the cooling water pipe to the hot surface of the cooling wall was $80 \mathrm{~mm}$. The thickness of the packing layer between the cooling wall and hearth lining was $50 \mathrm{~mm}$. The volumetric utilization efficiency of the BF was $2.5 \mathrm{t} /\left(\mathrm{m}^{3} \cdot \mathrm{d}\right)$. The cooling water velocity of the sidewall was $1.5 \mathrm{~m} / \mathrm{s}$, and the tapping temperature was $1500{ }^{\circ} \mathrm{C}$. Calculation using Equations (10)-(13), the equivalent convective heat transfer coefficient of the cold surface of the hearth lining, was $101.0 \mathrm{~W} /\left(\mathrm{m}^{2} \cdot \mathrm{K}\right)$ under normal production. After calculating, the temperature distribution of the hearth is shown in Figure 5. It can be seen that under the forced cooling of the external cooling system, the temperature of the hot iron near the hearth lining gradually decreased. The whole hearth presented a temperature distribution pattern of high inside and low outside, providing the necessary conditions for forming the solidified iron layer. 


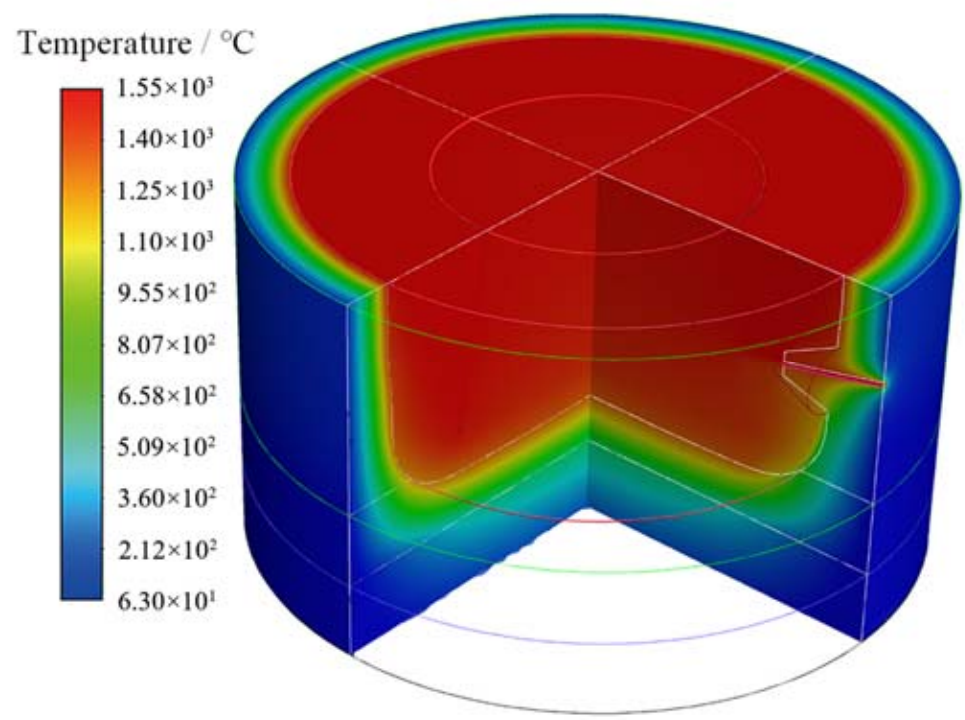

Figure 5. The temperature distribution of the normal production model.

The streamline of hot iron inside the hearth is shown in Figure 6. Because the porosity of the deadman is small, the hot iron was prevented from flowing inside the deadman. Most of the hot iron flows through the periphery and the bottom of the deadman to form a circulation phenomenon. In addition, almost no hot iron flowed through the local depressed erosion area. This indicates that the solidified iron protective layer had formed in this area under the current production conditions.

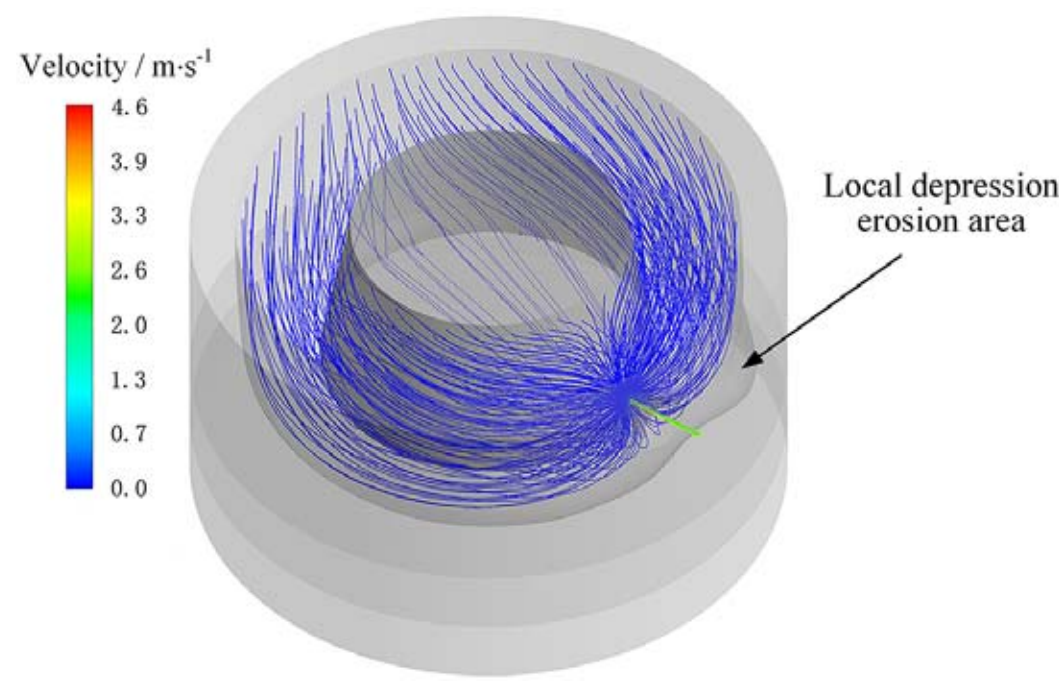

Figure 6. The hot iron streamline of the normal production model.

The calculation results of the axial section (defined as section $C$ ) and the furnace cross-section (defined as section D) are shown in Figure 7. The axial section is located in the direction of local depression erosion. The furnace cross-section is located $2400 \mathrm{~mm}$ from the furnace bottom. The volume fraction of hot iron on sections $C$ and $D$ is shown in Figure $7 \mathrm{a}, \mathrm{c}$. It can be seen that the volume fraction of hot iron near the depression erosion area is 0 , indicating that the solidified iron protective layer appeared at this position. When hearth lining erosion occurs, the thermal resistance of the erosion area is reduced. Under the same external cooling conditions, the cooling rate of hot iron in this area is faster. It is more conducive to the formation of a solidified iron layer. Therefore, it can be considered that the hearth has a certain "self-repairing" ability under the normal production heat transfer conditions. The velocity distribution of hot iron in section $C$ and D are shown in 
Figure $7 \mathrm{~b}, \mathrm{~d}$. The velocity of hot iron in the solid-liquid mushy zone is significantly reduced. This indicates that the solidified iron layer and mushy zone can effectively alleviate the erosion of hot iron flow on the lining.

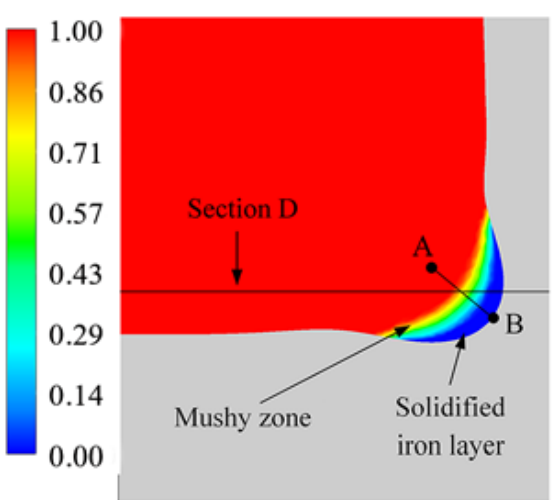

(a)

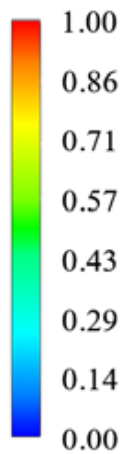

0.00

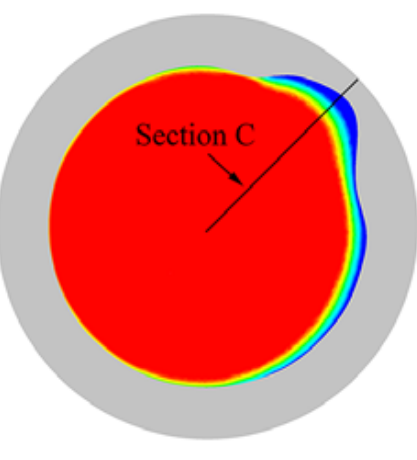

(c)
Velocity $/ \mathrm{m} \cdot \mathrm{s}^{-1}$

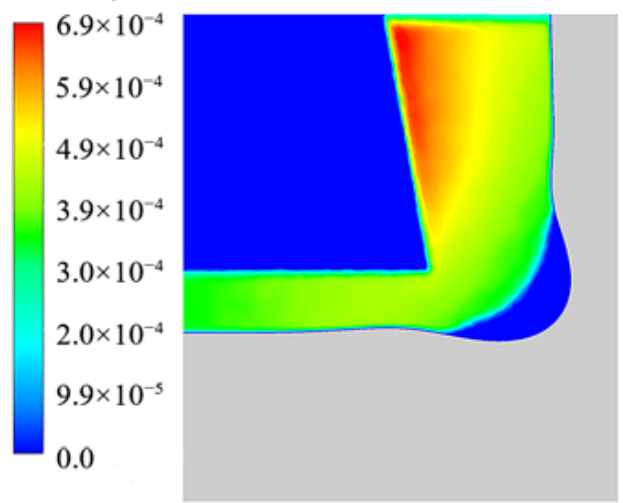

(b)

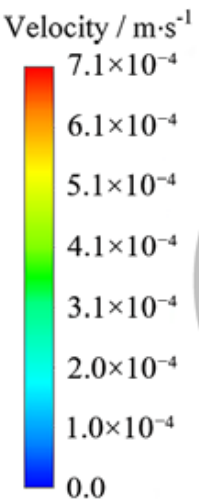

0.0

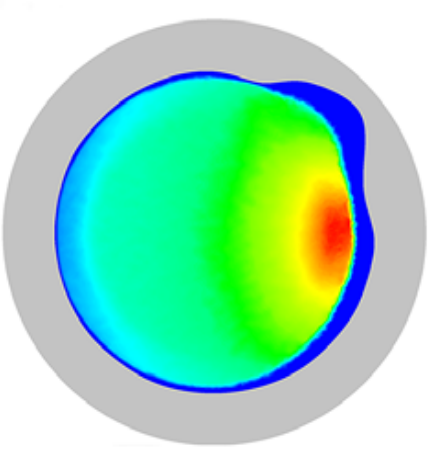

(d)

Figure 7. Calculation results of normal production. (a) volume fraction of hot iron at section C. (b) hot iron flow rate at section C. (c) volume fraction of hot iron at section D. (d) hot iron flow rate at section D.

\subsection{The Effect of Cooling Intensity on Depression Erosion}

The cooling intensity of the hearth is related to the cooling water flow, hearth structure, and the existence of an air gap. In this study, the hearth was a non-top masonry structure. There was a $50 \mathrm{~mm}$ packing layer between the lining and the cooling stave. In normal production, the equivalent convective heat transfer coefficient of the cold lining surface is 101.0 W/ $\left(\mathrm{m}^{2} \cdot \mathrm{K}\right)$. Another general hearth structure is the top lining structure. There was no packing layer between the lining and the cooling stave. If the top lining structure is adopted, the actual equivalent convection heat transfer coefficient of the cold surface can reach $173.0 \mathrm{~W} /\left(\mathrm{m}^{2} \cdot \mathrm{K}\right)$.

In the actual production process, thermal deformation and gas channeling will occur in the furnace. That often leads to the formation of air gaps in the furnace. The thermal conductivity of air at $100{ }^{\circ} \mathrm{C}$ is only $0.031 \mathrm{~W} /(\mathrm{m} \cdot \mathrm{K})$, so the existence of the air gap has a great impact on the heat transfer state of the hearth. Through calculation, when there is a $2.0 \mathrm{~mm}$ air gap between the hearth cooling stave and the lining, the actual equivalent convection heat transfer coefficient is $13.4 \mathrm{~W} /\left(\mathrm{m}^{2} \cdot \mathrm{K}\right)$. The cooling effect is greatly reduced.

The volume fraction of hot iron on section $\mathrm{C}$ of the top lining hearth and the hearth with a $2 \mathrm{~mm}$ air gap are shown in Figure 8. Figure $8 \mathrm{a}$ is the calculation result of the top lining structure. Compared with Figure $7 \mathrm{a}$, the change of the solidified iron layer is not obvious. Figure $8 \mathrm{~b}$ is the calculation result of the hearth with a $2.0 \mathrm{~mm}$ air gap. The solidified iron layer in the depression erosion area has completely disappeared, leaving only 
the mushy area. This is the same as the conclusion of the experiment in the literature [10]. The existence of the air gap directly destroys the stable thermal cycle state of the hearth and further affects the formation of the solidified iron layer in the hearth lining. Without the protection of the solidified iron layer, the erosion of hot iron on the lining of the hearth further intensifies. The local depression erosion area will further expand, which seriously affects the safety life of the hearth.

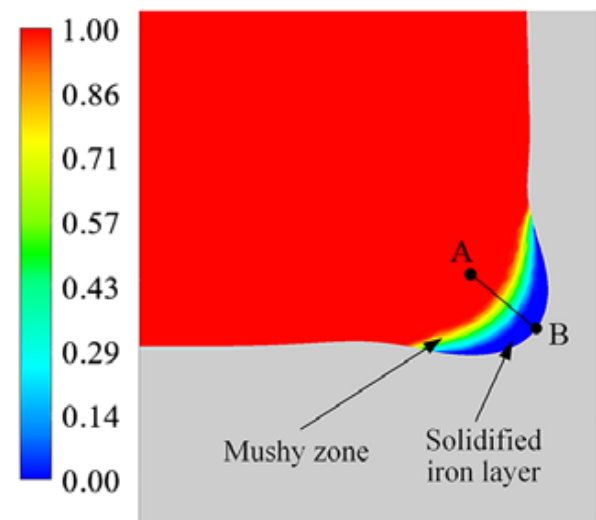

(a)

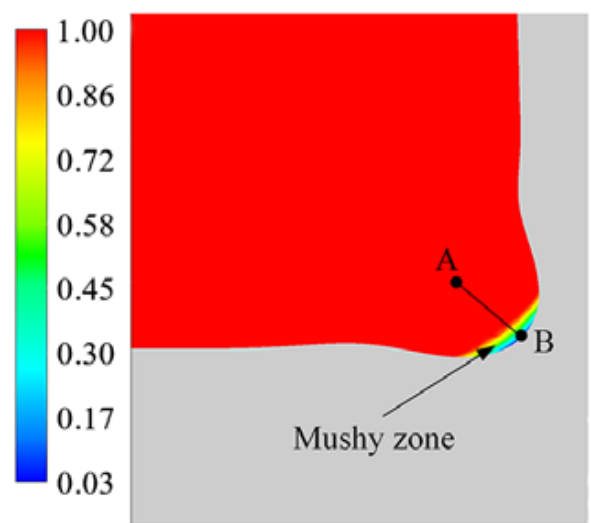

(b)

Figure 8. The volume fraction of hot iron on section C. (a) top lining structure. (b) model with $2 \mathrm{~mm}$ air gap.

Figure 9 is the volume fraction of hot iron on the evaluation line under different cooling intensities. It can be found that when the top lining structure is adopted, the position of the solidification point of hot iron (the volume fraction of hot iron is 0 ) has moved about $30 \mathrm{~mm}$ into the furnace. After increasing the cooling intensity, the heat exchange between the hot iron and the hearth increases, further reducing the temperature of the hot surface of the hearth. Compared with the normal heat transfer state, the furnace with the top lining structure is more conducive to the formation of the solidified iron layer.

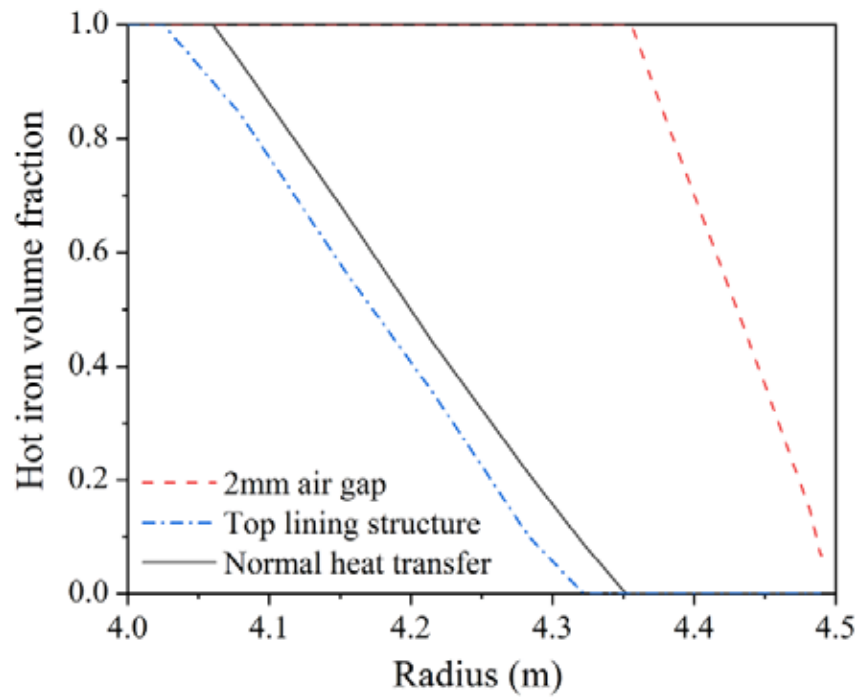

Figure 9. The volume fraction of hot iron on the evaluation line at different cooling intensities.

It can be concluded that the greater the equivalent convective heat transfer coefficient of the cold surface is, the more beneficial to the formation of the solidified iron layer. Increasing the cooling water velocity is a general measure to improve the cooling intensity of the hearth. When the cooling water velocity increases to $3.0 \mathrm{~m} / \mathrm{s}$, the actual equivalent convection heat transfer coefficient of the cold surface is about $109.0 \mathrm{~W} /\left(\mathrm{m}^{2} \cdot \mathrm{K}\right)$. And the 
cooling intensity increases by only $7.9 \%$. Therefore, it can be inferred that increasing the cooling water flow rate does not have a significant effect on alleviating depression erosion.

\subsection{The Effect of Closing Tuyere on Depression Erosion}

The chemical reaction above the closed tuyere is weakened after closing the tuyere. The amount of hot iron produced locally is reduced. The BF tuyere layout is shown in Figure 10. According to the position of the tuyere, the entrance of the calculation model was divided into equal parts accordingly. The mass flow of each inlet was loaded by area. After closing the tuyere, the hot iron flow at the corresponding inlet was set to zero.

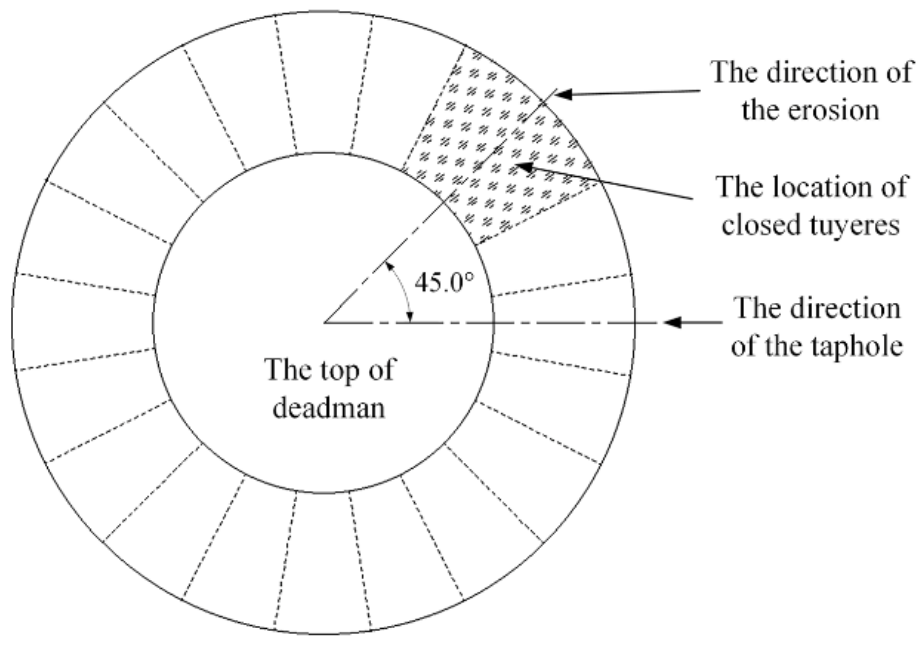

Figure 10. The positions of BF tuyeres.

The tuyere closing is often accompanied by the adjustment of the total blast volume of the BF. After reducing the blast volume, the tapping productivity of the BF is correspondingly reduced. The flow rate of hot iron at the inlet corresponding to the closed tuyere is set to zero. The adjusted tapping production rate and the inlet area of the unclosed tuyere are used to calculate the hot iron flow rate at the inlet. If the blast volume is not adjusted, the total BF tapping productivity remains unchanged. At this time, the hot iron flow at the closed tuyere is evenly distributed to the inlet at the unclosed tuyere.

As shown in Figure 11, the volume fraction of hot iron on the evaluation line decreased significantly after the two tuyeres were closed. The hot iron solidification critical point on the evaluation line moved about $38 \mathrm{~mm}$ to the inside of the hearth. After closing two tuyeres and reducing production by $10 \%$, the hot iron solidification critical point on the evaluation line moved about $59 \mathrm{~mm}$ to the inside of the hearth. This indicates that closing the tuyeres and reasonably controlling the production at the same time effectively alleviated the local depression erosion of the hearth. When the tuyere is closed, the hot iron flowing through the erosion location is reduced, and the heat near the erosion depression is reduced. It is conducive to the formation of the cast iron layer and slows down the development of hearth depression erosion.

\subsection{The Effect of Reducing Tapping Productivity on Depression Erosion}

Reducing tapping productivity is also one of the effective ways to alleviate the erosion of hearth lining [31]. The tapping productivity is generally expressed by the volumetric utilization coefficient of the BF. In this study, the volume utilization coefficient of the BF in normal production was $2.50 \mathrm{t} /\left(\mathrm{m}^{3} \cdot \mathrm{d}\right)$. The corresponding hot iron inlet flow rate was $60.96 \mathrm{~kg} / \mathrm{s}$. The calculation models were established to simulate the simulation of a $10 \%$ and $20 \%$ reduction in production. The corresponding hot iron inlet flow rates were $54.86 \mathrm{~kg} / \mathrm{s}$ and $48.77 \mathrm{~kg} / \mathrm{s}$. 


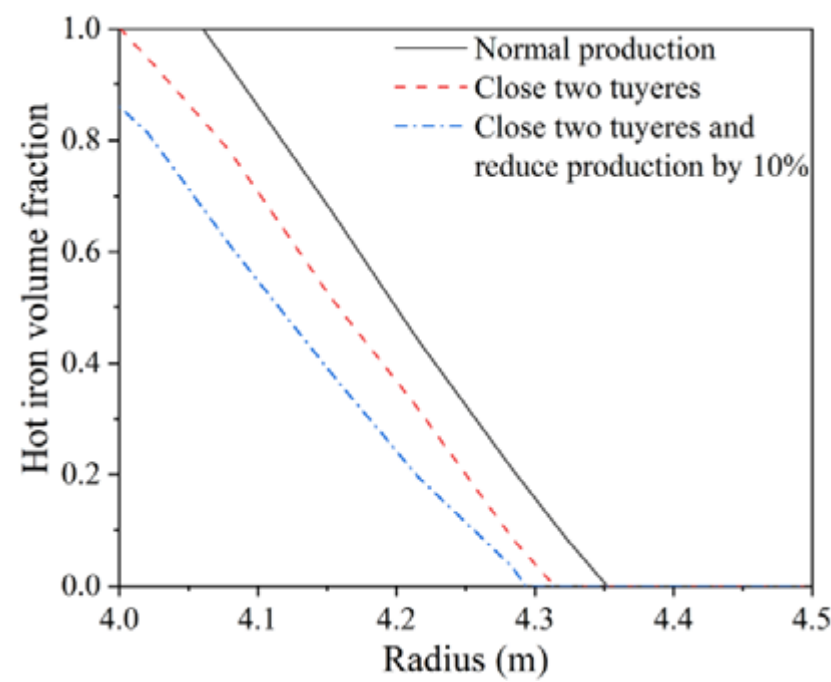

Figure 11. The volume fraction of hot iron on the evaluation line after tuyere closing.

The volume fraction of hot iron on the evaluation line after the reduction of production is shown in Figure 12. After reducing production by $10 \%$ and $20 \%$, the solidification point of hot iron moved about $34 \mathrm{~mm}$ and $51 \mathrm{~mm}$ to the inside of the furnace. This indicates that the more production reduces, the thicker the solidified iron layer that forms inside the hearth. The volume fraction of hot iron on section $\mathrm{D}$ after reducing production by $20 \%$ is shown in Figure 13. Compared with Figure 7c, the solidified iron layer and solid-liquid mushy zone expanded. It can be concluded that reducing the productivity of tapping effectively slows the further erosion of the hot iron to the hearth.

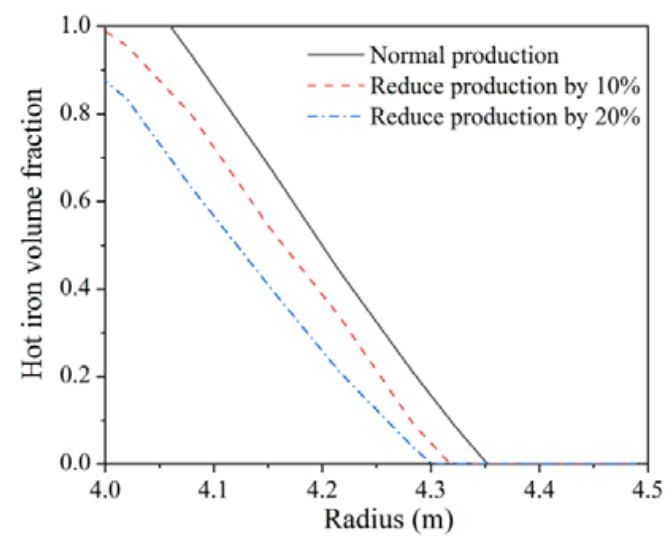

Figure 12. The volume fraction of hot iron on the evaluation line after production reduction.

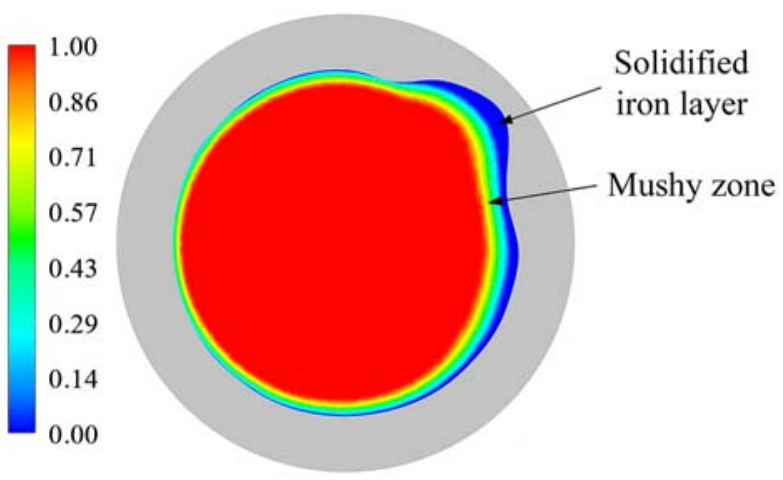

Figure 13. The volume fraction of hot iron on section D after $20 \%$ production reduction. 


\subsection{The Effect of Tapping Temperature on Depression Erosion}

The temperature inside the hearth affects the erosion of the lining. The tapping temperature is used to indirectly reflect the temperature inside the hearth. The normal tapping temperature of the BF ranges from $1480{ }^{\circ} \mathrm{C}$ to $1520^{\circ} \mathrm{C}$. In this study, three models of tapping temperature were calculated. The temperatures were $1480.1^{\circ} \mathrm{C}, 1500.0^{\circ} \mathrm{C}$, and $1519.7^{\circ} \mathrm{C} .1500^{\circ} \mathrm{C}$ is the temperature selected in the normal production model.

The volume fraction distribution of hot iron on section $C$ is shown in Figure 14. Compared with Figure 7a, when the tapping temperature decreases, the thickness of the solidified iron layer increases. The solid-liquid mushy zone moves to the inside of the hearth. After the tapping temperature rises, the solidified iron layer becomes thinner. The solid-liquid mushy zone moves to the outside of the hearth.

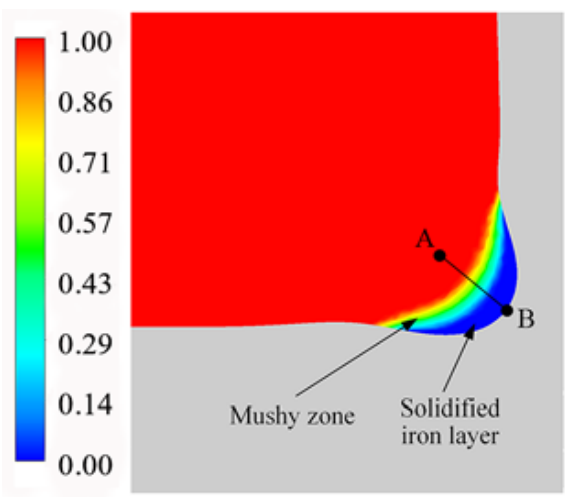

(a)

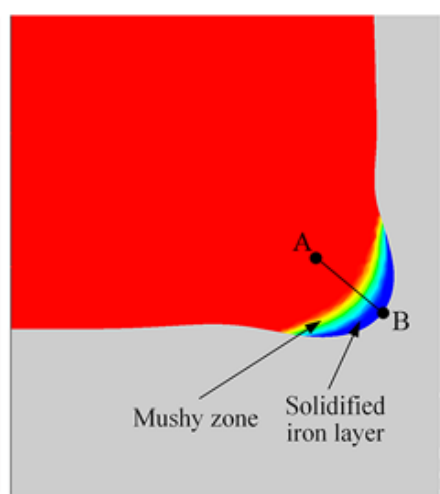

(b)

Figure 14. The volume fraction of hot iron on Section C: (a) $1480.1{ }^{\circ} \mathrm{C}$ tapping temperature; (b) $1519.7^{\circ} \mathrm{C}$ tapping temperature.

The volume fraction of hot iron on the evaluation line is shown in Figure 15. When the tapping temperature dropped from $1500.2^{\circ} \mathrm{C}$ to $1480.1^{\circ} \mathrm{C}$, the critical solidification point of the hot iron on the evaluation line moved about $44 \mathrm{~mm}$ to the inside of the hearth. When the tapping temperature increased from $1500.2{ }^{\circ} \mathrm{C}$ to $1519.7^{\circ} \mathrm{C}$, the critical point of the hot iron solidification on the evaluation line moved about $38 \mathrm{~mm}$ to the outside of the hearth. Compared with Figure 12, it is found that the effect of a $20.1^{\circ} \mathrm{C}$ reduction in the temperature of tapping is close to the effect of a $20 \%$ reduction in production. The temperature of the hot iron significantly affects the solidified iron layer in the depression erosion area. The hot iron is the direct source of heat inside the hearth. When the temperature of the hot iron decreases, the total heat entering the hearth decreases. The overall drop in the temperature of the hearth promotes the formation of the solidified iron layer.

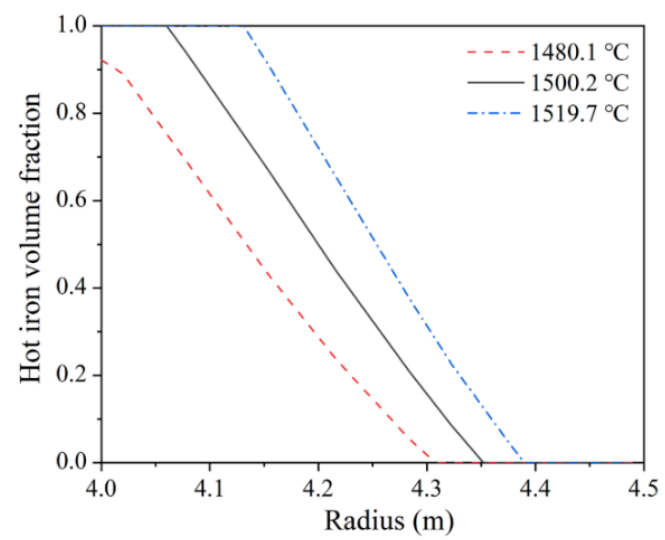

Figure 15. The volume fraction of hot iron on the evaluation line under different tapping temperatures. 


\section{Conclusions}

Based on the theory of heat transfer and computational fluid dynamics, a thermofluid coupling simulation model of a BF hearth with elephant-type depression erosion was established. The various furnace protection measures were analyzed and studied using the model. The analysis results were consistent with actual production experience. The research results of this paper provide a research basis for quantitative evaluation of the furnace protection effect. The main conclusions are as follows:

The air gap has a great influence on heat transfer in the furnace. When an air gap exists, the depression erosion area will further expand. The hearth with a top lining structure is more conducive to forming a solidified iron layer, which can effectively alleviate the depression erosion. Increasing the cooling water velocity helps slow the erosion of depression erosion, but the effect is limited.

After closing the tuyeres, the thickness of the solidified iron layer increases. Closing the tuyere is practical and effective for relieving depression erosion. The thickness of the solidified iron layer increases greatly after reducing the productivity of the BF. The reduction of BF productivity can effectively alleviate erosion. Under the premise of meeting the production demand, the productivity can be appropriately reduced to prolong the operational life of the BF. After reducing the tapping temperature, the thickness of the solidified iron layer increases significantly. Alleviating local depression erosion by controlling the temperature of hot iron is feasible. Regarding the twin premises of ensuring hearth activity and not affecting subsequent transportation, the tapping temperature should be adjusted appropriately to extend the life of the hearth.

Author Contributions: Conceptualization, L.W. and L.C.; methodology, L.C.; software, L.W.; validation, L.W., Y.L. and J.M.; formal analysis, Y.L.; investigation, J.M.; resources, L.C.; data curation, Y.L.; writing-original draft preparation, L.W.; writing-review and editing, L.W.; visualization, Y.L.; project administration, L.C.; funding acquisition, J.M. All authors have read and agreed to the published version of the manuscript.

Funding: This research received no external funding.

Institutional Review Board Statement: Not applicable.

Informed Consent Statement: Not applicable.

Data Availability Statement: The data that support the findings of this study are available from the corresponding author upon reasonable request.

Conflicts of Interest: The authors declare no conflict of interest.

\section{References}

1. Shibata, K.; Kimura, Y.; Shimizu, M.; Inaba, S. Dynamics of dead-man coke and hot metal flow in a blast furnace hearth. ISIJ Int. 1990, 30, 208-215. [CrossRef]

2. Huang, C.E.; Du, S.W.; Cheng, W.T. Numerical investigation on hot metal flow in blast furnace hearth through CFD. ISIJ Int. 2008, 48, 1182-1187. [CrossRef]

3. Liu, Z.J.; Zhang, J.Z.; Zuo, H.B.; Yang, T.J. Recent progress on long service life design of Chinese blast furnace hearth. ISIJ Int. 2012, 52, 1713-1723. [CrossRef]

4. Shao, L.; Saxen, H. Model of blast furnace hearth drainage. Steel Res. Int. 2012, 83, 197-204. [CrossRef]

5. Choi, J.; Han, K.W.; Cho, B.R. Long term high performance operation at Kwangyang blast furnaces. Rev. Met. Paris 2004, 101, 211-218. [CrossRef]

6. Andreev, K.; Louwerse, G.; Peeters, T.; van der Stel, J. Blast furnace campaign extension by fundamental understanding of hearth processes. Ironmak. Steelmak. 2017, 44, 81-91. [CrossRef]

7. Deng, Y.; Zhang, J.L.; Jiao, K.X. Economical and efficient protection for blast furnace hearth. ISIJ Int. 2018, 58, 1198-1203. [CrossRef]

8. Filatov, S.V.; Kurunov, I.F.; Gordon, Y.M.; Tikhonov, D.N.; Grachev, S.N. Extending the campaign life of an intensively operating blast furnace. Metallurgist 2017, 60, 905-911. [CrossRef]

9. Chen, W.C.; Cheng, W.T. Numerical simulation on forced convective heat transfer of titanium dioxide/water nanofluid in the cooling stave of blast furnace. Heat Mass Transf. 2016, 71, 208-215. [CrossRef] 
10. Shao, L.; Taskinen, P.; Jokilaakso, A.; Saxen, H.; Qu, Y.X. An experimental technique for investigating the skulling behavior in the blast furnace hearth. Steel Res. Int. 2019, 90, 1800297. [CrossRef]

11. Jiao, K.X.; Zhang, J.L.; Liu, Z.J.; Deng, Y.; Chen, C.L. Cooling phenomena in blast furnace hearth. J. Iron Steel Res. Int. 2018, 25, 1010-1016. [CrossRef]

12. Dong, X.F.; Zulli, P.; Biasutti, M. Prediction of blast furnace hearth condition: Part II-a transient state simulation of hearth condition during blast furnace shutdown. Ironmak. Steelmak. 2020, 47, 561-566. [CrossRef]

13. Deng, Y.; Zhang, J.L.; Jiao, K.X. Residual thickness of carbon brick calculation model and systematic analysis of heat transfer. Metall. Res. Technol. 2017, 114, 210. [CrossRef]

14. Shinotake, A.; Ootsuka, H.; Sasaki, N.; Ichida, M. Blast furnace campaign life relating to the productivity. Rev. Met. Paris 2004, 101, 203-209. [CrossRef]

15. Jiao, K.X.; Zhang, J.L.; Liu, Z.J.; Liu, F.; Liang, L.S. Formation mechanism of the graphite-rich protective layer in blast furnace hearths. Int. J. Miner. Metall. Mater. 2016, 23, 16-24. [CrossRef]

16. Jiao, K.X.; Zhang, J.L.; Liu, Z.J.; Chen, C.L.; Liu, Y.X. Analysis of blast furnace hearth sidewall erosion and protective layer formation. ISIJ Int. 2016, 56, 1956-1963. [CrossRef]

17. Zhao, Y.F.; Fu, D.; Lherbier, L.W.; Chen, Y.; Zhou, C.Q.; Grindey, J.G. Investigation of skull formation in a blast furnace hearth Steel Res. Int. 2013, 85, 891-901. [CrossRef]

18. Raipala, K. Deadman and hearth phenomena in the blast furnace. Scand. J. Metall. 2000, 29, 39-46. [CrossRef]

19. Shao, L.; Zhang, C.B.; Qu, Y.X.; Saxen, H.; Zou, Z.S. Numerical Simulation of Hot Metal Carbonization by Dead-Man Coke in the Blast Furnace Hearth. Steel Res. Int. 2020, 91, 1900460. [CrossRef]

20. Zhang, Y.; Deshpande, R.; Huang, D.; Chaubal, P.; Zhou, C.Q. Numerical analysis of blast furnace hearth inner profile by using CFD and heat transfer model for different time periods. Int. J. Heat Mass Transf. 2008, 51, 186-197. [CrossRef]

21. Guo, B.Y.; Maldonado, D.; Zulli, P.; Yu, A.B. CFD modelling of liquid metal flow and heat transfer in blast furnace hearth. ISIJ Int 2008, 48, 1676-1685. [CrossRef]

22. Brännbacka, J.; Saxén, H. Model analysis of the operation of the blast furnace hearth with a sitting and floating dead man. ISIJ Int 2003, 43, 1519-1527. [CrossRef]

23. Niu, Q.; Cheng, S.S.; Xu, W.X.; Niu, W.J.; Mei, Y.G. Analysis of the coke particle size distribution and porosity of deadman based on blast furnace hearth dissection. ISIJ Int. 2019, 59, 1997-2004. [CrossRef]

24. Chattopadhyay, K.; Isac, M.; Guthrie, R.I.L. Applications of Computational Fluid Dynamics (CFD) in iron-and steelmaking: Part 1. Ironmak. Steelmak. 2010, 37, 554-561. [CrossRef]

25. Panjkovic, V.; Truelove, J.S.; Zulli, P. Numerical modelling of iron flow and heat transfer in blast furnace hearth. Ironmak. Steelmak. 2002, 29, 390-400. [CrossRef]

26. Li, Y.; Chen, L.Y.; Wang, L.; Ma, J.C. Monitoring the safety status of a blast furnace hearth using cooling stave heat flux. AIP Adv. 2020, 10, 025308. [CrossRef]

27. Sheikholeslami, M. Numerical simulation of magnetic nanofluid natural convection in porous media. Phys. Lett. A 2017, 381, 494-503. [CrossRef]

28. Sheikholeslami, M. New computational approach for exergy and entropy analysis of nanofluid under the impact of Lorentz force through a porous media. Comput. Meth. Appl. Mech. Eng. 2019, 344, 319-333. [CrossRef]

29. Koponen, A.; Kataja, M.; Timonen, J. Permeability and effective porosity of porous media. Phys. Rev. E 1997, 56, 3319. [CrossRef]

30. Liu, X.; Chen, L.G.; Feng, H.J.; Sun, F.R. Constructal design for blast furnace wall based on the entransy theory. Appl. Therm. Eng. 2016, 100, 798-804. [CrossRef]

31. Jiao, K.X.; Zhang, J.L.; Hou, Q.F.; Liu, Z.J.; Wang, G.W. Analysis of the relationship between productivity and hearth wall temperature of a commercial blast furnace and model prediction. Steel Res. Int. 2017, 88, 1600475. [CrossRef] 